\title{
Comments on: Implications of structural variations in the human sacrum: why is an anatomical classification crucial?
}

\author{
Juan Mario García-Coronado ${ }^{1}$ A. G. Espinosa-Uribe ${ }^{1} \cdot$ F. Vílchez-Cavazos ${ }^{2}$ • \\ A. Quiroga-Garza ${ }^{1}$ R. E. Elizondo-Omaña ${ }^{1} \cdot$ S. Guzmán-López ${ }^{1}$
}

Received: 19 May 2016/Accepted: 11 July 2016/Published online: 18 July 2016

(C) Springer-Verlag France 2016

To the editor;

We sincerely appreciate the work done by Mahato [1] in which a qualitative classification of the sacrum is done to determine the number of segments, position of auricular surfaces, symmetry and abnormalities. This work is of the utmost importance since it is crucial for several surgical interventions and at the same time correlates certain pathologies with the morphology, mostly low back pain.

It would be of great benefit having a quantitative study of the sacrum, like the one performed by our working group, Morales et al. [2], in which the morphometric characteristics (sacral foramina, pedicles, vertebral body and sacral canal) of 50 sacral specimens in Mexican population were obtained. With this information it is possible to determine the most prevalent characteristics that are present in the sacrum in Mexican population, which are critical for a safe intervention and compare them with the existing literature. In our work it was possible to establish that the pedicle length of S1 was longer than reported in previous studies.

We recommend performing a similar study to the working group of Mahato, in which the morphometric characteristics of the sacral in Indian population are obtained, with this adding valuable information to the

R. E. Elizondo-Omaña

rod_omana@yahoo.com

1 Department of Human Anatomy, Faculty of Medicine, Universidad Autónoma de Nuevo León (U.A.N.L.), Ave. Madero y Dr. Eduardo Aguirre Pequeño s/n, Col. Mitras Centro, 64460 Monterrey, Nuevo León, México

2 Orthopedics and Traumatology Service, University Hospital “Dr. José Eleuterio González", Universidad Autónoma de Nuevo León (U.A.N.L.), Monterrey, Nuevo León, México proposed classification in predicting the most prevalent measures. This would give a chance to have safer procedures after having done a clinical correlation of the pathology based on Mahato [1] and predict the sacrum measurements based on a similar study to ours, with this having correct screw placement and position in lumbosacral instrumentation, and also for other procedures that involves the sacral region as surgical and diagnostic target.

The classification proposed by the working group of Mahato is of essential importance since it correlates the form and characteristics of the sacrum with the patient symptoms and gives valuable information to the surgeon that will perform a procedure. Besides, it presents information on the several variations present on the sacrum to be able to identify them. We consider it is important to take into account both analyses [1,2].

Compliance with ethical standards

Funding No funds were received in support of this work.

\section{References}

1. Mahato NK (2016) Implications of structural variations in the human sacrum: why is an anatomical classification crucial? Surg Radiol Anat. doi:10.1007/s00276-016-1667-0

2. Morales-Ávalos R, Leyva-Villegas JI, Vílchez-Cavazos F, Martínez-Ponce de León ÁR, Elizondo-Omaña RE, Guzmán-López S (2012) Morphometric characteristics of the sacrum in Mexican population. Its importance in lumbosacral fusion and fixation procedures. Cir Cir 80(6):528-535 